\title{
ZILINA UNIVERSITY CONCEPT OF DIGITAL FACTORY
}

This paper focuses on the Digital Factory technologies, the areas of their application, as well as its benefits for industry. The paper presents the Digital Factory concept built in the framework of co-operation of the University of Zilina and the Central European Institute of Technology (CEIT).

Key Words: Digital Factory, Virtual reality, Simulation, Digital Mock Up (DMU)

\section{Introduction}

Digital manufacturing and product lifecycle management could be the edge that manufacturers in a global economy need to deliver high-quality products with the quickest time to market. Digital manufacturing enables to eliminate errors in the production line, human or mechanical. Product Lifecycle Management (PLM) represents above introduced vision.

Different types of software are linked in PLM solutions, which control different parts of the manufacturing cycle. Computer Aided Design (CAD) systems define what will be produced. Manufacturing Process Management (MPM) defines how it is to be built. Enterprise Resources Planning (ERP) answers when and where it is built. Manufacturing Execution System (MES) provides shop floor control and simultaneously manufacturing feedback. The storing of information digitally aids communication, but also removes human error from the design and manufacture process.

The products innovations are the topic of current discussions. There exists almost no discussion about innovations of production and assembly systems, in spite of the fact that the majority of foreign investment in Eastern Europe was focused in production and assembly.

The Virtual Reality can be used as by the product development as by the design of production processes, workplaces, production systems, etc. The utilization of Virtual Reality by the design and optimisation of production processes and systems is often entitled as Digital Factory [1].

\section{Digital Factory}

Digital Factory entitles virtual picture of a real production. It represents the environment integrated by computer and information technologies, in which the reality is replaced by virtual com- puter models. Such virtual solutions enable to verify all conflict situations before real implementation and to design optimised solutions.

Digital Factory supports planning, analysis, simulation and optimisation of complex products production and simultaneously creates conditions and requires team work. Such solution enables quick feedback among designers, technologists, production systems designers and planners.

Digital Factory represents integration chain between CAD systems and ERP solutions, as it is shown in the following Figure.

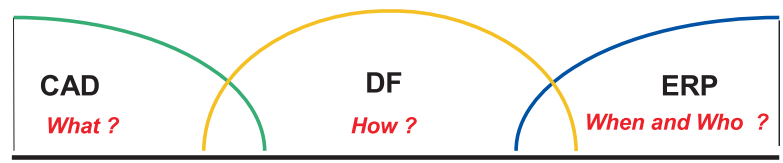

Fig. 1 Integration of Information Systems in Production [3]

One of very important properties of Digital Factory is the vision to realize process planning and product development with parallel utilisation of common data.

- Digital Factory principle is based on three parts:

- digital product, with its static and dynamic properties,

- digital production planning and,

- digital production, with the possibility of utilisation of planning data for

- enterprise processes effectiveness growth.

It is very important to gain all required data only one time and then to manage them with the uniform data control, so that all software systems will be able to utilize it. The integration is one of the main conditions for the implementation of Digital Factory.

\footnotetext{
* Milan Gregor, Stefan Medvecky

Central European Institute of Technology, University of Zilina, Slovakia, E-mail: milan.gregor@fstroj.uniza.sk
} 


\subsection{Digital Factory application area}

Digital Factory is appropriate mainly as a support for the batch manufacturing of high sophisticated products, their planning, simulation and optimisation. Its main current application area is automotive industry, mechanical engineering industry, aerospace and ship building industry as well as electronics and consumer goods industries [2].

3D digital model of products (DMU - Digital Mock Up) creates currently basic object for the work in digital manufacturing environment [5]. There exists possibility to optimise products, processes and production systems even by the development phase with the utilisation of 3D visualisation and modelling techniques. This solution brings time to market reduction and significant cost reduction [4]. Such complex 3D models are currently known as so called FMU (Factory Mock Up).

The system for the design of shop floor 3D layouts and generation of $3 \mathrm{D}$ models of production halls is missing in current Digital Factory solutions [6]. It is possible to create the 3D model of production hall directly in CAD systems. Such solution is advantageous by new layouts or by new production systems designs.

But, production halls do exists, in majority of real cases. By such conditions, it is often more effective to create $3 \mathrm{D}$ model of production hall with the utilisation of Reverse Engineering technologies and 3D laser scanners [5].

The material flow simulation enables to optimise the movement of material, to reduce inventories and to support value added activities in internal logistics chain [7].

The subsystems for effective ergonomics analysis utilise international standards as The National Institute for Occupational Safety and Health (NIOSH), Rapid Upper Limb Assessment (RULA), etc., which enable right planning and verification of man-machine interactions on the single workplaces.

The highest level of analysis is represented by a computer simulation of production and robotics systems which enables optimisation of material, information, value and financial flows in the factory [5].

The Digital Factory solutions enable visualisation and 3D modelling in ergonomics analyses. They offer simultaneously all international standards for ergonomics analyses.

\subsection{Digital Factory Advantages}

Digital Factory implementation results directly in economic as well as production indicators improvement. Any slight saving realised in a design and planning phase can bring huge cost reduction in a production operation phase. Thanks to this is payback period by investment in Digital Factory very short.
Digital Factory advantages [5]:

- reduction of entrepreneurship risk by the introduction of a new production,

- processes verification before start of production,

- possibility of virtual "visit" of production halls,

- validation of designed production concept,

- optimisation of production equipment allocation,

- reduction in required area,

- bottlenecks and collisions analysis

- fast changes,

- better utilization of existing resources,

- machines and equipment off line programming saving time and resources,

- reduction or full elimination of prototypes,

- ergonomics analyses, etc.

Digital Factory enables to test and reveal all possible production problems and shortages before start of production.

The highest potentials for high quality and low costs of products are in product development and production planning phases. The statistics show that product design and production planning influence about $80 \%$ of production costs [3].

Digital Factory enables product launching time reduction up to $25-50 \%$. Estimated cost savings are supposed from 15 to $25 \%$. According to some studies done in industry, using digital manufacturing techniques, twice the amount of design iterations can be processed in 25 percent of the time.

The current production equipment is often inflexible by quick changes. That is why the designers of such equipment are looking for new solutions (automatic reconfiguration of production machines) with fully automated control systems, which will be able to find optimized production process and parameters after production task definition.

According to CIMdata report (March 2003), Digital Factory enables to achieve following financial savings:

- Cost savings by assets reduction about $10 \%$,

- Area savings by layout optimisation about $25 \%$,

- Cost savings by better utilisation of resources about $30 \%$,

- Cost savings by material flows optimisation about $35 \%$,

- Reduction in number of machines, tools, workplaces about $40 \%$,

- Total cost reduction about $13 \%$,

- Production volumes growth about $15 \%$,

- Time to market reduction about $30 \%$.

\section{Digital Factory implementation methodology}

Rough procedure of Digital Factory implementation is as follows [3]:

Definition of total standards and production principles for entire planning operations, creation of primitives and customer databases, 
First data collection and organisation with the utilisation of data management system. All responsible persons have direct access to the date, their addition, inspection and changes,

In this phase, Digital Factory system improves co-ordination and synchronisation of individual processes throughout their "networking" supported by workflow management system,

In the fourth phase, Digital Factory system takes automatically some routine and checking activities, which are very time consuming in common systems. Implemented system insures high quality of all outputs.

\section{Digital Factory at the University of Zilina}

The University of Zilina became the first university in Eastern Europe which uses software solutions for Digital Factory in education and research [5]. The University of Zilina in co-operation with the Central European Institute of Technology started to build their own Digital Factory concept whose structure is shown in Fig. 2.

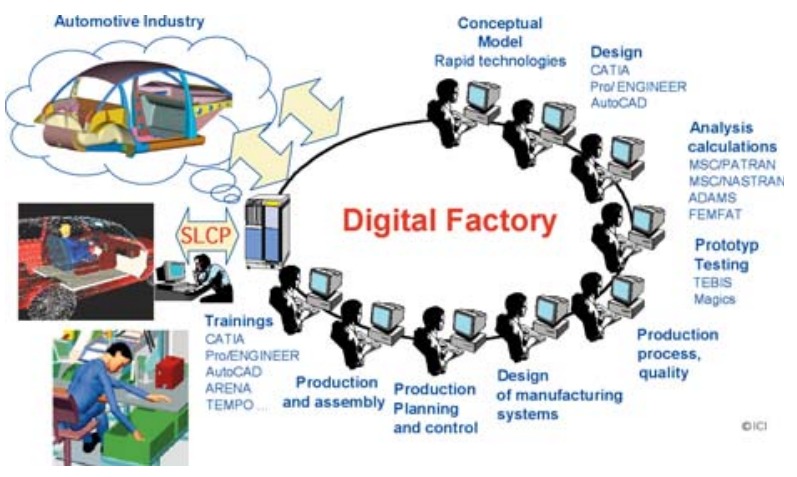

Fig. 2 Digital Factory Concept Built at the University of Zilina [5]
This concept increases the borders of current Digital Factory solutions. It endeavours to integrate activities conducted by designers, technologists, designers of manufacturing systems, planners. It simultaneously tries to increase the offer of individual existing modules. The concept design goes from theoretical studies as well as practical experience gained in industry in Slovakia (VW Slovakia, Whirlpool Slovakia, PSL, etc.).

\section{The Digital Factory supports the choice of an appropriate shop floor control strategy}

There exist a plenty of production control strategies. Among them, the most known are: Material Requirements Planning (MRP), Load Oriented Control (LOC), Drum Buffer Rope (DBR), Constant Work In Process (CONWIP), KANBAN and Input/Output Control. Fig. 3 describes the basic principles of CONWIP and DBR production control strategies.

The Digital Factory offers the simulation and virtual reality, in general, as the support tools for the analysis of complex systems. The authors developed and validated the procedure for the choice of an appropriate shop floor control strategy for a given production system configuration. This procedure was than applied in a decision process by the choice of an appropriate production control strategy in industry. Further on the authors used metamodelling to simplify the chosen control of the given production system.

The production managers can operate production system either by low throughput times and inventories or by high utilization of capacities. Those control strategies are mutual exclusive. Fig. 4 shows the so called "Production Control Dilemma".

Modelling of large systems such as hierarchical models of entire enterprises require high computing power which is multiplied by utilisation of 3D animation with virtual reality features. Simulation is a time consuming technique. There exists possibility

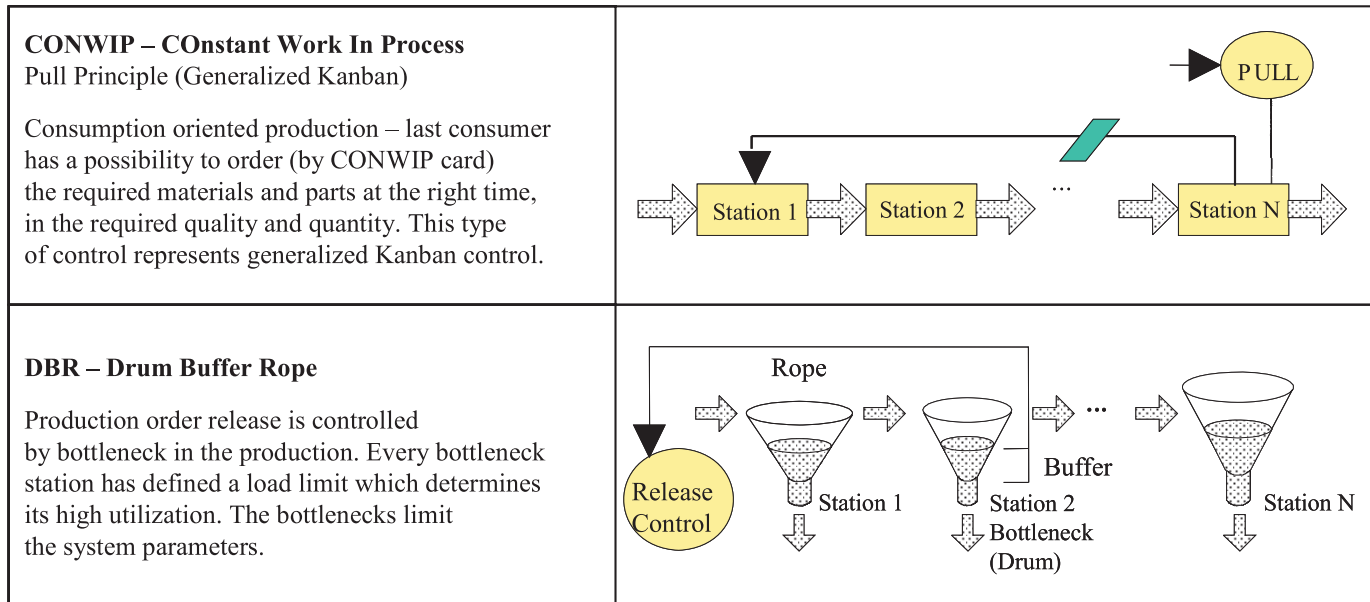

Fig. 3 CONWIP and DBR Production Control Strategies [3] 

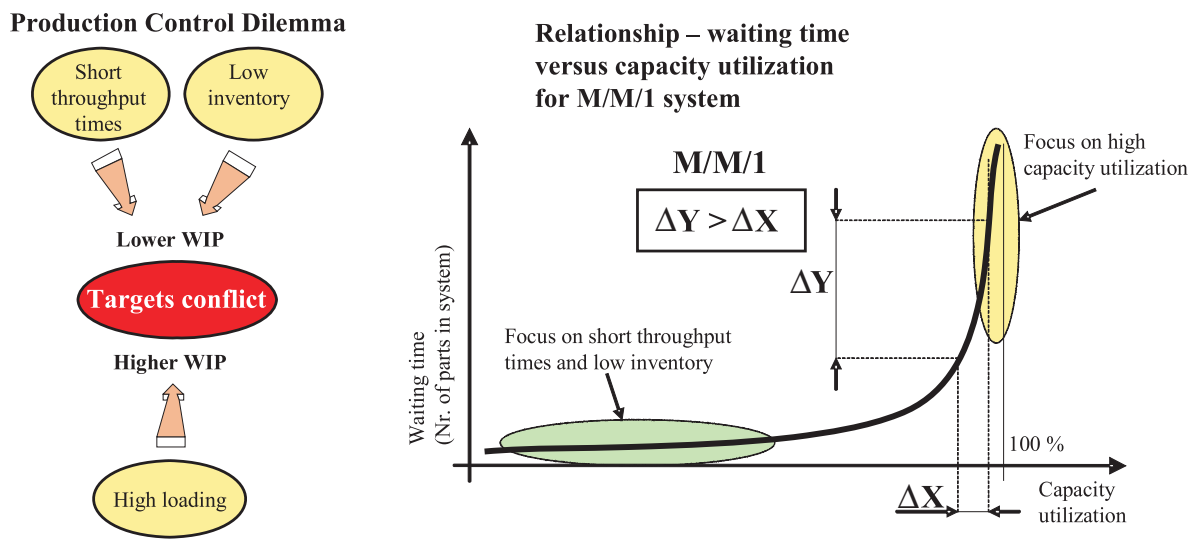

Fig. 4 Production Control Dilemma

to replace very complicated and complex simulation models by validated metamodells and on this way to fasten the decision making process in industry. Metamodelling offers practical approach to the statistical summarisation of simulation results. It enables a given extrapolations in the framework of simulated conditions borders and the fast approximate manufacturing systems control.

The principle of metamodelling is similar to the hierarchical modelling (see following Fig. 5).

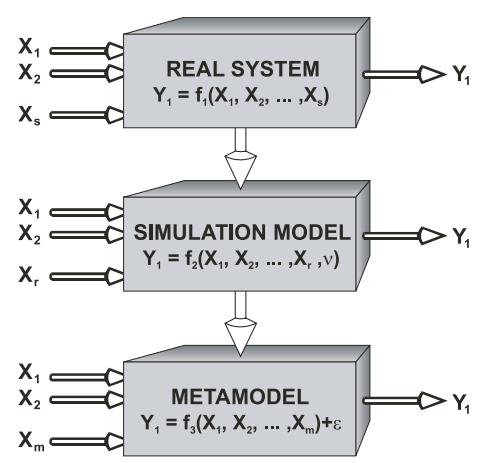

Fig. 5 Metamodelling Principles

Following Fig. 6 shows the proposed procedure for the design and validation of metamodells.

To be able to achieve a short response in forecasting of manufacturing system behaviour under a given control strategy, the below described manufacturing system metamodell was developed. Simulation was used for testing the responses of the production system to the proposed changes of chosen control factors. The set of possible control strategies (KANBAN, CONWIP, DBR, LOC and MRP) was tested with using of the proposed metamodell.

Following part, taken from a comprehensive theoretic and applied study conducted in Slovak industry, contains chosen results for CONWIP control strategy [4].

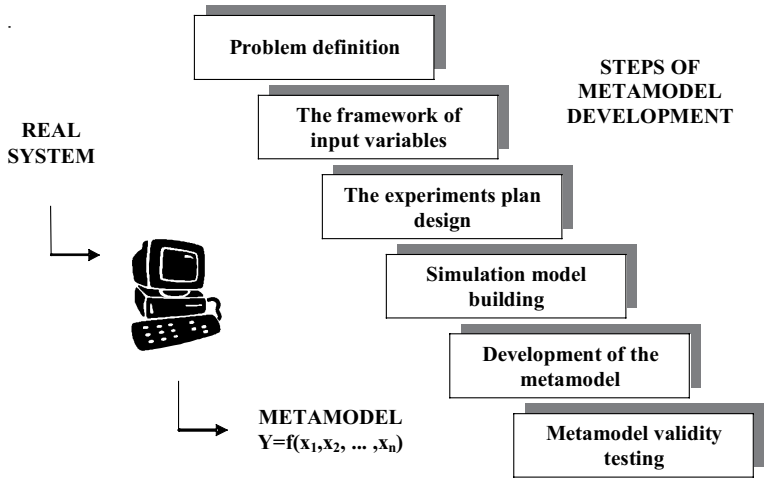

Fig. 6 Steps of metamodel development

Summarization of the simulation results

Table 1.

\begin{tabular}{|c|c|c|c|c|c|c|}
\hline Experiment & E1 & E2 & E3 & E4 & E5 & E6 \\
\hline $\begin{array}{l}\text { No. of Conwip } \\
\text { Cards }\end{array}$ & 1 & 2 & 3 & 4 & 5 & 8 \\
\hline Avg. Time (min) & 61.04 & 61.27 & 62.06 & 64.11 & 75.87 & 118.91 \\
\hline WIP (pc) & 0.99 & 1.99 & 2.99 & 3.99 & 4.99 & 7.99 \\
\hline Production (pc) & 16 & 32 & 47 & 60 & 63 & 63 \\
\hline Experiment & E7 & E8 & E9 & E10 & E11 & \\
\hline $\begin{array}{l}\text { No. of Conwip } \\
\text { Cards }\end{array}$ & 11 & 14 & 17 & 20 & 23 & \\
\hline Avg. Time (min) & 158.47 & 197.42 & 233.13 & 268.01 & 299.26 & \\
\hline WIP (pc) & 10.99 & 13.99 & 16.99 & 19.99 & 22.99 & \\
\hline Production $(\mathrm{pc})$ & 64 & 64 & 64 & 63 & 64 & \\
\hline
\end{tabular}

The number of CONWIP cards directly determines the level of work-in-process inventories in the system and so influences the average throughput time of production orders and the total through- 
put of the production system as well. The mathematical relationships and their graphical presentation are shown as follows.

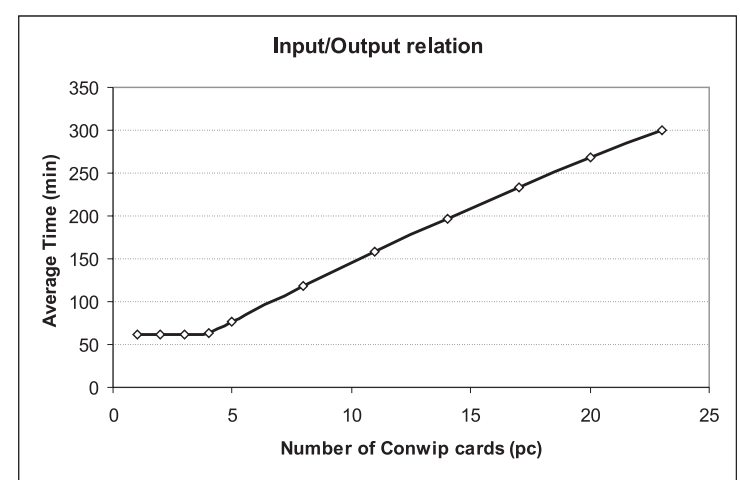

Fig. 7 Relationship between the Number of CONWIP Cards and Average Throughput Time

The relationships among control factors and production parameters were described by using of regression analysis. The behaviour of complex manufacturing system using given control strategy was substituted by its simplified mathematical models (metamodells). The statistical validation (fitting of mathematical model to the simulation output data) was tested by $R^{2}$.

Results of regress analysis

Table 2.

\begin{tabular}{|l|l|l|}
\hline Type of trend & Trend function & $R^{2}$ \\
\hline linear & $y=11.734 x+30.209$ & 0.9899 \\
\hline logarithmic & $y=79.865 \ln (x)-6.099$ & 0.8097 \\
\hline exponential & $y=53.637 e^{0.0825 \cdot x}$ & 0.9642 \\
\hline polynomial II. & $y=0.0767 x^{2}+9.9704 x+35.993$ & 0.9913 \\
\hline polynomial III. & $\begin{array}{l}y=-0.0277 x^{3}+1.0712 x^{2}+0.5603 x+ \\
+54.248\end{array}$ & 0.9973 \\
\hline polynomial IV. & $\begin{array}{l}y=0.0028 x^{4}-0.1603 x^{3}+3.0816 x^{2}+ \\
+10.028 x+68.259\end{array}$ & 0.9994 \\
\hline polynomial V. & $\begin{array}{l}y=-0.0002 x^{5}+0.014 x^{4}-0.399 x^{3}+ \\
+5.189 x^{2}+17.241 x+75.134\end{array}$ & 0.9997 \\
\hline
\end{tabular}

$R^{2}$ was calculated as follow:

$$
R^{2}=1-\underset{S S T}{S S E}, 0 \leq R^{2} \leq 1,
$$

where $S S E=\sum\left(Y_{i}-\bar{Y}_{i}\right)$ and $S S T=\sum\left(Y_{i}^{2}\right)-\frac{\left(\sum Y_{i}\right)^{2}}{n}$.

Next Figure shows the comparison of several models with the original simulation data. It is evident that the trends with $R^{2}$ close to one give the best results.

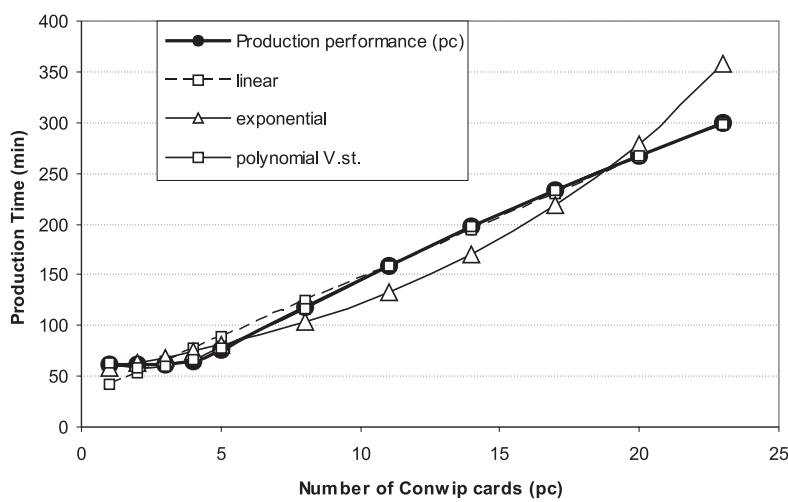

Fig. 8 Comparison of Chosen Models

The developed metamodel offers possibility to find out very quickly and without using simulation the production parameters (e.g. average throughput time, WIP, etc.). The mutual comparison of results from simulation and metamodelling shows insignificant difference $(0.0319 \mathrm{~min})$. The part of results of the metamodel validation are shown in the following table. The metamodel is valid on region from one to 22 cards.

Verification of the metamodel

Table 3.

\begin{tabular}{|l|c|c|c|c|c|c|c|}
\hline $\begin{array}{l}\text { Comparison } \\
\text { of average } \\
\text { production } \\
\text { time }\end{array}$ & \multicolumn{7}{|c|}{ Number of Conwip cards } \\
\cline { 2 - 8 } & 6 & 7 & 10 & 12 & 15 & 19 & 22 \\
\hline Simulation & 89.52 & 104.62 & 145.84 & 173.09 & 210.14 & 256.89 & 290.20 \\
\hline $\begin{array}{l}\text { Metamodel- } \\
\text { ling }\end{array}$ & 89.20 & 102.69 & 145.28 & 172.31 & 209.45 & 255.71 & 288.28 \\
\hline
\end{tabular}

The following Figure shows the whole region of metamodel validity. The problem started by using the number of cards over 22 . The deviation by 30 cards was significant and so it showed that it

\section{Polynomial trend of the 5-th degree}

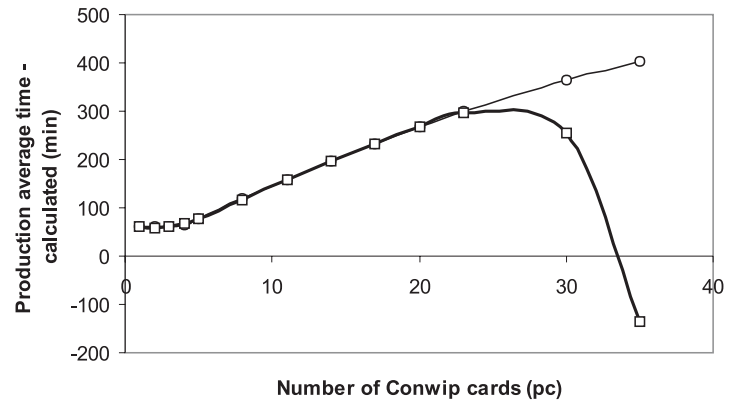

Fig. 9 Progress of the Metamodel Equation Using Polynomial Trend of 5-th Degree 
was not appropriate to use polynomial equation of the 5-degree as a substitution of simulation data for these values.

The results of the study showed the possibility to simplify the decision making process by the control of complex production systems in the framework of Digital Factory environment.

\section{Digital Factory for industry}

The further development and prosperity of any country depends on quality of its engineers responsible for innovations. Investment into education brings almost 8 times higher increase of productivity than investment in capital assets.

The University of Zilina has conducted several research studies in industry. In the framework of co-operation with VW Slovakia the DMU model of a real gearbox was developed. The FMU of the whole assembly line for gearboxes assembly in VW was developed for training purposes. A new 3D digital model of production system was developed in co-operation with PSL, a.s. Povazska Bystrica

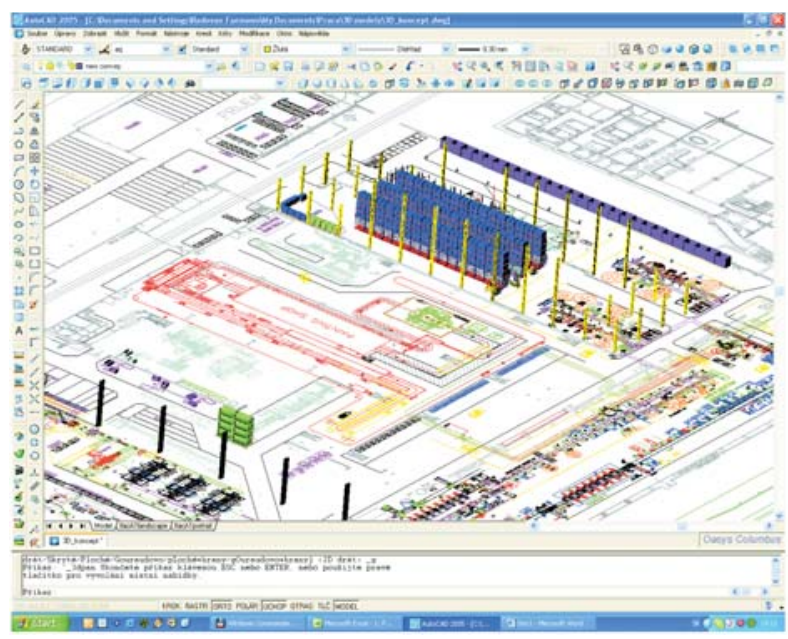

Fig. 10 Digital Model of Production System - Whirlpool Slovakia [3]

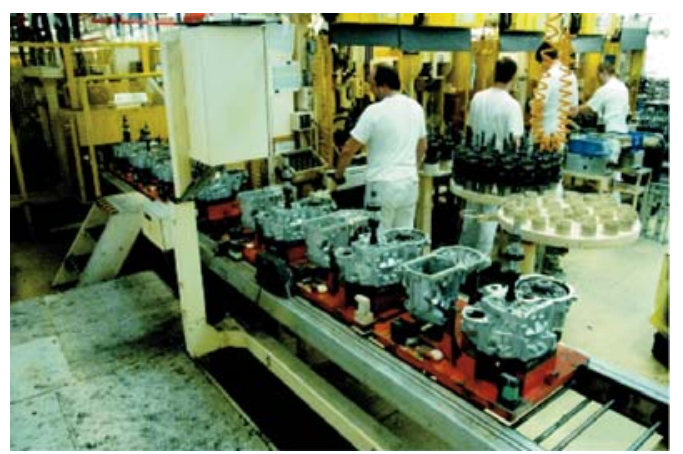

The models of chosen workplaces were developed in co-operation with Whirlpool Slovakia. Following figures show some chosen results.

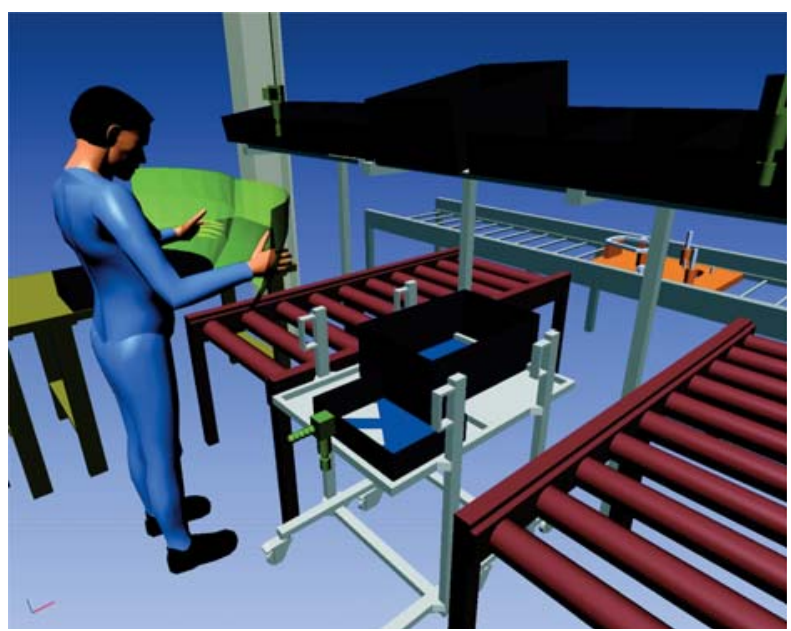

Fig. 12 VW Slovakia - Digital Model of Manual Workplace [3]

\section{Conclusion}

The future outlook shows that next generation products can benefit from digital manufacturing. Any type of process elements are stored so that as modifications are made at any stage of product development, they are made to the entire design and manufacturing process.

Current research requires huge investment. The governments support innovative research only partially. Our industry also requires Digital Factory solutions. Unfortunately till now it has not been woken up and apart from a few exceptions there is little willingness for investment into research and development.

Every university is obliged to educate students who will be able to design competitive products and production systems with

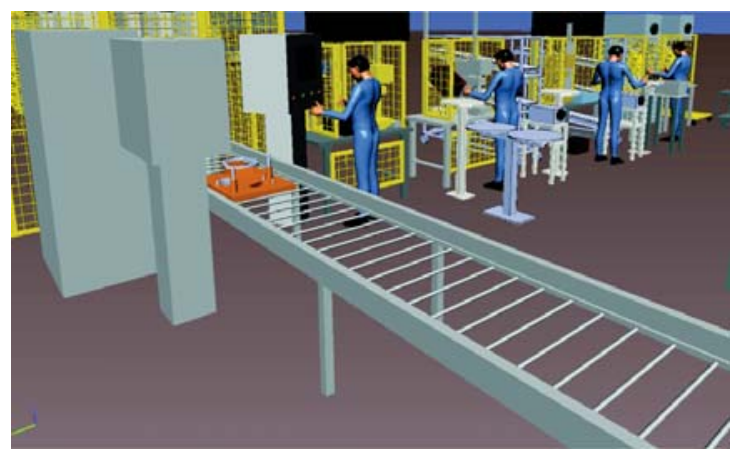

Fig. 11 VW Slovakia - Real Versus - 3D Digital Model [3] 


\section{COMMNICAIIONS}

the help of advanced information technologies. The common intention of the University of Zilina is to establish a fully integrated system for the design of sophisticated production systems with its main focus on automotive and electronics industries. Such a system should enable to bring new technologies into industry as well as into education and simultaneously to support the education of future designers, designers of manufacturing systems, technologists and managers.

\section{References}

[1] FURMANN, R., GREGOR, M.: Virtual Design - How to be Closer to the World Class? (in Slovak), Informatyka, Organizacja i Zarzadzanie, ATH Bielsko Biala, 2005, pp. 35-40, ISSN 1644-0315,

[2] GREGOR, M. et al.: Virtual Reality Technology as a Support for Competitiveness and Productivity Improvement (in Slovak), University of Zilina. Research project, No.: APVT-20-026304,

[3] GREGOR, M. et al.: Research of Possible Utilization of Digital Factory in the Slovak Industry (in Slovak), University of Zilina, Research project, No.: AV 4/0021/05,

[4] GREGOR, M., STEFANIK, A., HROMADA, J.: Lean Manufacturing Systems Optimisation Supported by Metamodelling. In: Lean Business Systems and Beyound. Springer, New York, 2008, pp. 175-184, ISBN 978-0-387-77248-6

[5] GREGOR, M., MEDVECKY, S., MICIETA, B., MATUSZEK, J., HRCEKOVA, A.: Digital Factory, SLCP Zilina, KRUPA print 2007, ISBN 80-969391-5-7. 148 pp.

[6] MICIETA, B. et al: Virtual Reality in Sophisticated Assembly Processes (in Slovak), University of Zilina, Research project, No.: AV $1014 / 2003$,

[7] STEFANIK, A., GREGOR, M.: Rapid Development of the new Production System with the Support of Computer Simulation, Rapid technologies, Wroclaw, CAMT, October 2004, pp.234-242. 